\title{
MEASURING PROCESS RISK \\ IN INCOME PROTECTION INSURANCE
}

\author{
BY
}

Steven Haberman, Zolan Butt and Ben Rickayzen

\begin{abstract}
The main objective of this paper is to measure the process error for a portfolio of independent disability insurance policies in a multiple state modelling context. We consider the calculation of premiums for a portfolio of income protection insurance policies in a stochastic environment represented both by random transitions in the underlying multiple state model and random external economic factors in the form of stochastic investment returns and inflation. We also investigate the sensitivity of the process error to the level of volatility incorporated in a given model using suitably defined risk measures. We then draw conclusions and identify possible avenues for future research.
\end{abstract}

\section{KEYWORDS}

Income protection insurance, asset and liability process risk, insolvency, riskbased capital, risk-loaded premium, multiple state models.

\section{INTRODUCTION}

Describing and quantifying the risks involved in health related products are becoming increasingly more important as insurance companies endeavour to respond to the demand for such products, created by external economic trends (e.g. the increasing numbers of self-employed) and demographic changes (e.g. the ageing of the population), noting that this type of business has caused substantial losses in the past. The objective of this paper is to consider the calculation of premiums for a portfolio of simple disability insurance policies in a stochastic environment represented both by random transitions in the underlying multiple state model and random external economic factors (i.e. factors not under the control of the insurer). The disability insurance product which we examine is now called income protection insurance, IPI (or simply IP) but was formerly known as permanent health insurance (PHI) in the UK.

We will consider the risk in the portfolio that emanates from the sicknessclaims process (i.e. morbidity) and the risk attributable to the economic uncertainty represented by stochastic investment returns and inflation rates. We will 
also consider how this level of risk can be managed through, for example, a risk-loaded premium or through a solvency margin (i.e. risk-based capital) both of which can be determined from probabilistic calculations.

We note that all models abstract to some extent from the real world and, as noted by Daykin et al (1994) and other authors, models are subject to three broad types of error or risk:

model error

- because models are not known with certainty and usually are only approximations to the real world;

parameter error

- past observation data are limited in quantity and so parameters are not known with certainty;

process (or stochastic) error - our target quantities will be subject to random fluctuations about the mean, even when the model and parameters are correct.

Our focus will be on the third component: process error. The pooling of insured units in a portfolio is a critical part of the insurance process and, as demonstrated by Cummins (1991), leads to a reduction in the relative level of variability in the portfolio i.e. the risk per unit. This is a statement about process error - the other two types of error are not controllable in a comparable way. We note that external factors (for example, investment returns and inflation) have a systematic effect which affects all policies at the same time, so that the pooling of risks through writing more of the same business may not reduce the relative level of variability from this source: this is analysed in section 4 of the paper.

Before focusing on process error, we will make some comments at this stage about the two other types of error. Modelling a portfolio of disability insurance policies provides us with an example where model error could be important - there are, for example, at least three established methodologies for pricing and reserving of disability insurance products in use in the UK i.e. Manchester Unity, inception rates plus disability annuity approach and the multiple state model approach, although it is well argued that the multiple state model provides a framework within which the different models can be formulated successfully (CMI Committee (1991), Haberman and Pitacco (1999)). Practitioners in the UK have tended to abandon the Manchester Unity approach because of the model error associated with it and now use one of the other two approaches. For IP portfolios, we might expect that the parameter risk would be more significant than in life insurance because:

a) the underlying data are less reliable. For example:

- sickness inceptions with durations less than the deferred period are unobservable, making the data more scanty;

- claim times tend to be a round number of weeks;

b) the definition of sickness and of a claim are less clear cut, and are influenced by policy conditions. Thus, a company will need care in using unadjusted industry wide data, as provided by the CMI Bureau in the UK; 
c) sickness claims are often linked with socio-economic conditions and there is scope for moral hazard (Haberman (1987)).

Our main objective will be to identify ways of measuring the process error for a portfolio of independent income protection policies in a multiple state modelling context. A second objective will be to observe the extent to which the process error changes as we increase the volatility and complexity of the models generating investment returns and inflation. Thus, we start with a model that is based on random multiple state transitions and deterministic (i.e. expected) economic assumptions and then increase the volatility of this model by allowing for stochastic economic factors. In this way, we will be able to compare, in a specific case (i.e. for a particular policy), the magnitudes of the relative variability due to demographic process risks and due to demographic and economic process risks combined. Further, we will be able to identify and isolate the effect of different components of the process risks and ultimately to measure their impact on the proposed risk measures.

In life insurance, it is usual to consider the (liability) process risk as being relatively insignificant because claim amounts are fixed and portfolios tend to be large so that the law of large numbers and pooling lead to a reduction in process risk. However, Marceau and Gaillardetz (1999) have demonstrated that this effect operates differentially for different types of life insurance policy, with the mortality process risk being more significant for temporary insurances than for endowment insurances. In income protection insurance, there is variability in terms of claims incidence and size (i.e. measured by duration of time spent sick or disabled beyond the deferred period) and portfolios tend to be smaller than in life insurance, so that we might expect that liability process risk may not be negligible. This will be investigated in subsequent sections.

The paper is organised as follows. Section 2 describes the overall methodology. Section 3 describes in detail the models used and assumptions made, as well as introducing the four risk measures that will be used and the method of calculation of the premium. Section 4 describes and analyses a selection of the results obtained. Section 5 provides some concluding comments.

\section{Methodology}

We construct a simple asset-liability model of an insurer with only IP business using a multiple state model approach. Firstly, we simulate independent sample paths for individual policyholders occupying the healthy and sick states and moving between states, which are used to draw up a cumulative yearly experience over the policy term for the cohort of insured lives. Secondly, we simulate annual stochastic investment returns and stochastic inflation rates applying the widely accepted Wilkie model. We then construct a simple cash flow model for the portfolio and use the simulation results to construct useful financial quantities at the portfolio (or indeed company) level (see section 3).

In particular, we will consider four overall measures of risk, viz the probability of ruin and relative average shortfall for the portfolio and the levels of 
risk-based capital or risk-loaded premium to achieve a pre-specified probability of ruin. We will analyse and compare the results for three different models with increasing levels of volatility, that is:

a) stochastic sickness experience and deterministic economic factors, where the latter are obtained as the expected values of their stochastic counterparts: the Deterministic Assets Model (DAM). This class of model is intended to describe the set of simulations where the final outcomes are based on a stochastic morbidity experience and fixed (i.e. deterministic) economic factors (i.e. return on investment and cash-flow inflation rates). Using this model, we will be able to measure the process risk due to the demographic factors and quantify the effect of the demographic volatility in isolation on the important risk measures that we have defined.

b) stochastic sickness experience combined with stochastic investment experience and deterministic inflation rates: the Stochastic Assets Model 1 (SAM1). This second class of model is defined to capture the process risks resulting from the volatile nature of the morbidity experience and the uncertainty in the investment returns, while keeping the premium, benefits and expense inflation at a fixed level. In this type of model, the resulting asset returns are stochastic and less dependent on the size of portfolio. Intuitively, by comparing the outcomes of this group of simulations with those for DAM, we will be able to measure the process risk due to investment returns and evaluate the effect on the risk measures being considered.

c) a fully stochastic model, with all of the above demographic and economic factors randomised: the Stochastic Assets Model 2 (SAM2). In this third class of model, we further emphasize the influence of economic process risk in the proposed simulations by including also the effect of stochastic inflation on premiums, benefits and expenses. Therefore, we could consider the resulting model to be 'fully stochastic' having each of its important components randomised and time dependent, so that the model is brought closer to replicating a real IP office experience. However, this is not the actual purpose of this final model, since the results would heavily depend on the chosen parameter values. Instead, our principal objectives are to measure the process risk arising from introducing the extra randomness attributable to these economic factors and to quantify their effect on the above mentioned risk measures.

Figure 1 illustrates the above strategy by indicating the type of extra volatility added to each model.

stochastic

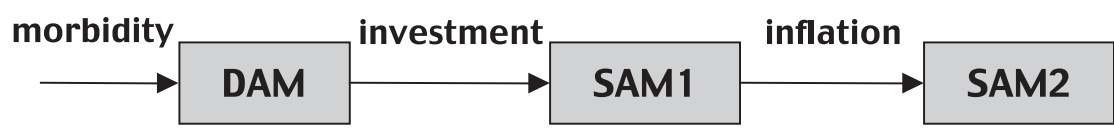

\section{deterministic}

FIGURE 1: Incorporated volatility structure of the defined asset-liability models. 


\section{Models And ASSUMPTIONS}

\subsection{Policy Design}

We consider a simple policy design with terminal age 65 and a range of entry ages: $\{30,40,50,60\}$ with zero lapse rates. Premiums are payable while the policyholder is either healthy or sick but for a period less than the deferred period (i.e. a no claim exclusion period). Benefits are payable as an annuity while the policyholder is sick for a duration longer than the deferred period. Various expenses are incorporated. The policy design is such that the premiums and benefits are guaranteed from the outset to increase in line with inflation, but are not altered to take account of the actual demographic or investment experience.

We note that the premium and benefit levels may vary significantly in the case of the stochastic inflation model, although in practice, this effect would be mitigated by market pressures. All regulatory requirements and taxation are ignored. Overall, we assume a homogeneous IP portfolio made up of a cohort

TABLE 1

SUMMARY OF CHOSEN POLICY DESIGN

\begin{tabular}{|c|c|c|c|}
\hline \multicolumn{4}{|r|}{ IP Policy Design } \\
\hline \multicolumn{2}{|c|}{ Deferred period: } & $(d)$ & 13 weeks \\
\hline \multirow{4}{*}{ Expenses: } & - Initial & $(e)$ & $£ 200$ at inception of policy (including commission) \\
\hline & \multirow{2}{*}{ - Renewal } & $\left(w_{0}\right)$ & $£ 25$ pa if the policyholder is healthy \\
\hline & & $\left(y_{0}\right)$ & $£ 95$ pa if the policyholder is sick \\
\hline & - Claim & $\left(z_{0}\right)$ & $\begin{array}{l}£ 200 \text { at inception of the claim (i.e. claim registration and claim } \\
\text { underwriting costs) }\end{array}$ \\
\hline \multicolumn{2}{|c|}{ Return on investment: } & $\left(r_{1}\right)$ & $\begin{array}{l}10.7 \% \text { pa expected rate of investment return for the deterministic } \\
\text { approach or Wilkie model for the stochastic approaches (see } \\
\text { section 3.3.1) }\end{array}$ \\
\hline \multirow{2}{*}{$\begin{array}{l}\text { Escalation } \\
\text { rates }\end{array}$} & - premium & $\left(e_{1}\right)$ & $\begin{array}{l}\text { 3\% pa expected inflation of premiums and benefits using both } \\
\text { deterministic (i.e. fixed) or stochastic (i.e. time series) approaches } \\
\text { (see section 3.3.2) }\end{array}$ \\
\hline & - expense & $\left(e_{2}\right)$ & $\begin{array}{l}4 \% \text { pa expected inflation of expenses using both deterministic } \\
\text { (i.e. fixed) or stochastic (i.e. time series) approaches (see sec- } \\
\text { tion 3.3.2) }\end{array}$ \\
\hline \multicolumn{2}{|l|}{ Premium: } & $\left(p_{0}\right)$ & $\begin{array}{l}£ 220 \text { pa for entry age } 30 \text { and similar levels for other entry ages } \\
\text { across different models (see section 3.6) }\end{array}$ \\
\hline \multicolumn{2}{|l|}{ Benefits: } & $\left(c_{0}\right)$ & $\begin{array}{l}£ 8,000 \text { pa while policyholder is sick, but subject to the require- } \\
\text { ments of the deferred period }\end{array}$ \\
\hline \multicolumn{2}{|c|}{ Ages at entry: } & $\left(x_{1}\right)$ & $30,40,50$ or 60 \\
\hline \multicolumn{2}{|c|}{ Termination age: } & $\left(x_{2}\right)$ & 65 \\
\hline
\end{tabular}


of independent policies and there is no possibility of their insurance cover being increased by starting additional contracts during the fixed term.

The detailed assumptions are presented in Table 1 and are intended to be representative of IP contracts in UK at the time of writing.

\subsection{The Demographic Model}

\subsubsection{Multiple State Model}

To describe the transitions, we have used the continuous time and three-state (i.e. discrete) healthy-sick-dead model (H, S, D), with the states labelled $S=\{1$, $2,3\}$ respectively. It should be noted that, given the universality of the multiple state technique, we can readily apply our methodology to other similar three-state models, for example active-disabled-dead, or indeed extend it with additional states like: 'short-term sick' and 'long-term sick' or 'lapsed' (Rickayzen, 2001), or apply it to other types of insurance cover, for example Long Term Care (see Haberman and Pitacco, 1999). The computing power needed to simulate a large number of stochastic transitions using multiple state models is no longer a problem, so we have available an excellent mathematical framework for modelling a complex insurance portfolio and determining the relevant measures of risk.

We consider an insured aged $x$ at entry and let $S(x+t)$ denote the random state occupied by the insured at age $x+t, t \geq 0$. We define the conditional probabilities

$$
{ }_{t} p_{x}^{i j}=\operatorname{Pr}[S(x+t)=j \mid S(x)=i]
$$

for $i, j \in\{1,2,3\}$ assuming the Markov property. For the specific applications here, we will only consider new policyholders who are healthy at their entry age $x_{1}$ (i.e. $S\left(x_{1}\right)=1$ ).

Then we define the transition intensities

$$
\mu_{x}^{i j}=\lim _{t \rightarrow 0}\left[\frac{{ }_{t} p_{x}^{i j}}{t}\right]
$$

For the functional form of the transition intensities we have adopted the graduated values obtained by CMI Committee (1991) from fitting to the males 1975-78 experience (for individual policies), as these have wide currency in the UK (although a less complex set of graduations has been proposed by Renshaw and Haberman (1995)).

Our intention is to consider a portfolio of policies with a deferred period of 13 weeks. Where appropriate we have chosen the graduated transition intensities that are consistent with this selection. For the transition intensities from state 2 (sick), there is strong evidence of dependence on sickness duration, $z$, (i.e. length of stay in state 2) leading to a semi-Markov framework. However, we have ignored this level of complexity and have used the relevant graduated 
values corresponding to $z=17$ weeks. These have been chosen because one of the reported features of the 1975-78 data (and other comparable data sets - see Renshaw and Haberman (1995)) is the reduced recovery rates during the first 4 weeks of claim. The choice of $z=17$ weeks for the 13 weeks deferred period policies, being considered here, avoids this anomaly.

Thus, the functional forms are as follows:

$$
\mu_{x}^{12}=\exp \left(a_{0}+a_{1} x+a_{2} x^{2}+a_{3} x^{3}\right)
$$

where $a_{0}=-2.722, a_{1}=0.1290, a_{2}=-4.240 \times 10^{-3}$ and $a_{3}=3.888 \times 10^{-5}$

$$
\mu_{x}^{13}=b_{0}+b_{1} y+\exp \left(b_{2}+b_{3} y\right)
$$

where $y=\frac{x-70}{50}, b_{0}=-4.652 \times 10^{-3}, b_{1}=-4.525 \times 10^{-3}, b_{2}=-3.986, b_{3}=3.185$

$$
\mu_{x}^{21}=c_{0}+c_{1}\left(x-c_{2}\right)
$$

where $c_{0}=3.086, c_{1}=-0.0927, c_{2}=50.326$

$$
\mu_{x}^{23}=\left(d_{0}+d_{1}\left(x-d_{2}\right)+d_{3}\left(x-d_{2}\right)^{2}\right) d_{4}+d_{5} \exp \left(d_{6} x\right)
$$

where $d_{0}=0.238, d_{1}=-4.819 \times 10^{-3}, d_{2}=0.326, d_{3}=9.587 \times 10^{-5}, d_{4}=0.537$, $d_{5}=7.221 \times 10^{-3}, d_{6}=2.435 \times 10^{-2}$.

We have carried out some tests for policies with deferred period other than 13 weeks and the results obtained are of a similar character to those reported in section 4. It is beyond the scope of this paper to provide any detailed results on the sensitivity to the choice of deferred period, however the results are available from the authors on request.

\subsubsection{Simulation and Thinning}

Our goal is to simulate a random morbidity experience (i.e. length of times spent in different states) for each life in the initial IP portfolio over the term of the policy. A convenient way to achieve this is by "thinning" as described in

$$
\begin{array}{ll}
\mathrm{H} \text { - healthy } & \mathrm{C} \text { - claiming } \\
\mathrm{S}-\text { sick } & \mathrm{D} \text { - dead }
\end{array}
$$

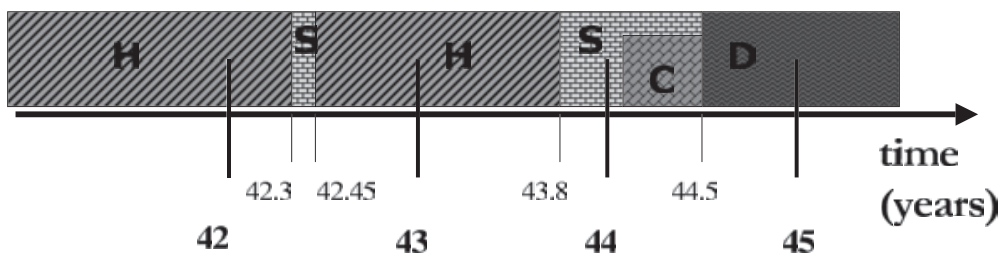

FIGURE 2: Example of a three-state model 'sample path'. 
Ross (1990) and utilised (in the actuarial literature) by Jones (1997) for modelling transitions in continuing care retirement communities. This method produces individual experiences (i.e. 'sample paths' - see Figure 2) that are independent of each other and identically distributed. The thinning procedure used to simulate an individual sample path is set out in detail in the flow chart in Figure 3 and a brief description of the process is given below.

We assume that all policyholders are healthy (i.e. in state 1) at entry at age $x_{1}$ with the prospect of either surviving the term to the final age $\left(x_{2}\right)$ or dying during the term. For IPI, the policies are designed so that a claim may be made only when the policyholder has been in the sick state for longer than the deferred period.

For a policyholder in state 1 at entry age $x_{1}$ at time 0 and a policy with term $m$ years we consider

$$
\alpha=\max _{x_{1} \leq x \leq x_{1}+m}\left(\mu_{x}^{12}+\mu_{x}^{13}\right)
$$

where the term in parentheses represents the transition intensity out of state 1 at age $x$, and $\alpha$ is chosen to be the maximum value of this overall intensity throughout the age range $\left[x_{1}, x_{1}+m\right]$.

We can generate 'jumps' (i.e. exits out of state 1) using a Poisson process with rate $\alpha$ since the intervals between successive event times would be exponentially distributed with parameter $\alpha^{-1}$. However, there would be too many such event times (i.e. exits) because of the definition of $\alpha$ in (7) and so we need to moderate or "thin" out the possible jumps. The probability of the occurrence of a simulated jump at time $t_{1}$ is proportional to the ratio:

$$
p_{1}=\frac{\mu_{x_{1}+t_{1}}^{12}+\mu_{x_{1}+t_{1}}^{13}}{\alpha} \text {. }
$$

Thus we accept the first exit time for which a simulated uniform random number $u_{2} \sim \mathrm{U}(0,1)$ is smaller than or equal to $p_{1}$. If $t_{1}^{*}$ is the time of the first accepted jump, then we need to establish whether the insured jumps to state 2 or state 3. For this purpose, we simulate a third uniform random number $u_{3} \sim$ $\mathrm{U}(0,1)$ and provided this is smaller than or equal to the ratio:

$$
p_{2}=\frac{\mu_{x_{1}+t_{1}^{*}}^{12}}{\mu_{x_{1}+t_{1}^{*}}^{12}+\mu_{x_{1}+t_{1}^{*}}^{13}} .
$$

we confirm the jump as being to the sick state (i.e. state 2). Otherwise, we accept the jump as being to the dead state (i.e. state 3 ).

Once the simulation has led to our deciding on the time and state of the first transition, we move forward to the next transition. We then determine $\alpha$ (over the age range $x_{1}+t_{1}^{*}$ to $x_{1}+m$ ) and proceed iteratively until we have a jump that takes the insured life beyond time $m$ or until death, whichever is sooner. 


\section{THINNING FLOW CHART}

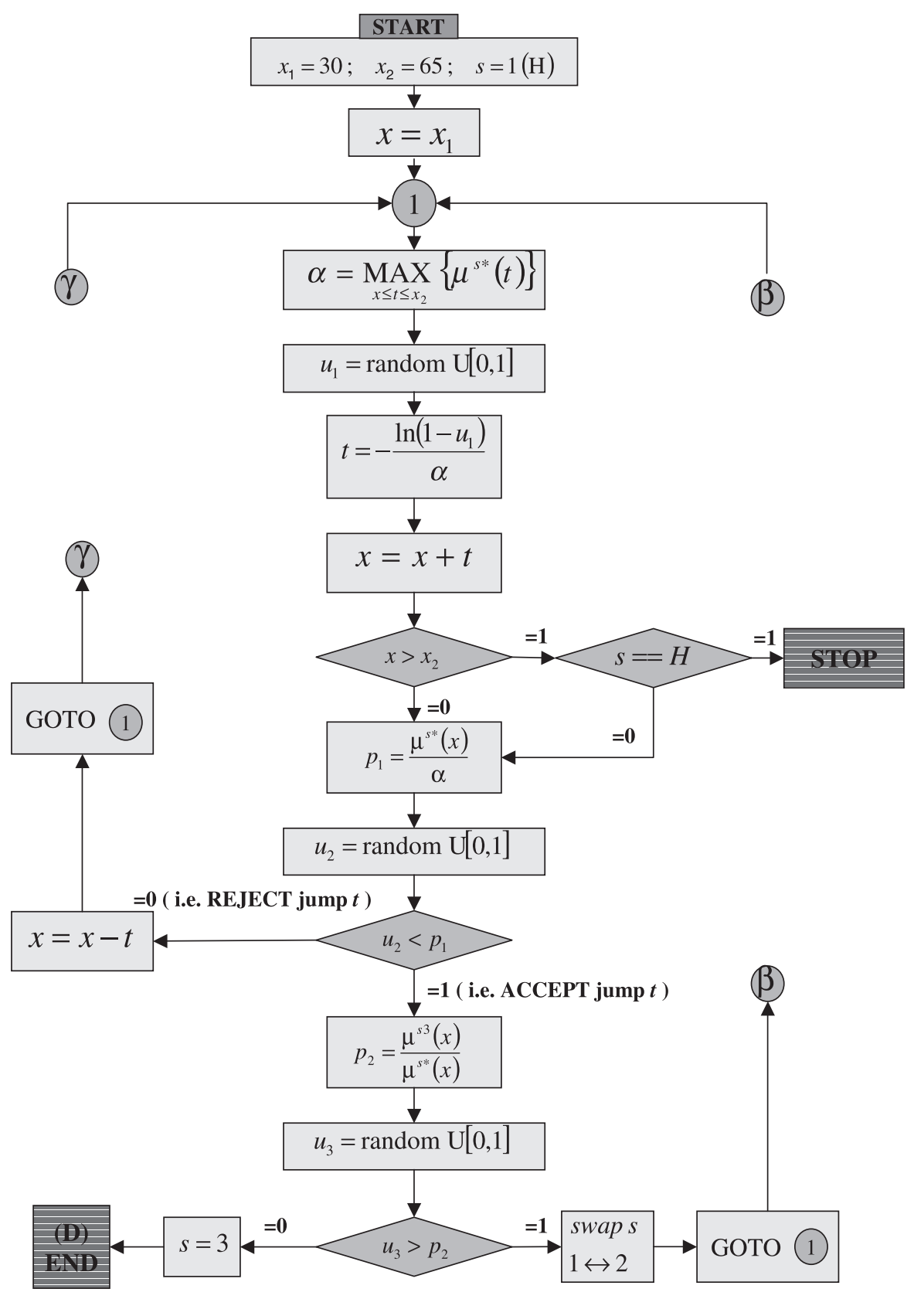

Reached end state

Change states $\mathbf{H}<->\mathbf{S}$

FIGURE 3: Logical Scheme of Simulation with Thinning. 
We note that there is a choice regarding a simulated jump time, $t$, which takes the path beyond time $m$ : we can accept this either with or without testing it using a random number $u_{2}$ against $p_{1}$, as in the standard thinning process. We have chosen the latter on the grounds of simplicity and have checked whether the former approach would markedly affect the results. Our conclusion is that there is little difference between the two approaches as far as the cumulative claim times (i.e. joint experience of all policyholders in the portfolio) in the vicinity of the terminal age $x_{2}$ are concerned.

\subsection{The Economic Model}

\subsubsection{Investment Returns Model}

In order to generate random investment returns for the SAM1 and SAM2 cases, we will use the widely accepted Wilkie model for equity returns and returns on index-linked government bonds. We use the structure of the model as in Wilkie (1995) and the initial parameter settings recommended therein. We consider an asset portfolio comprising 50\% equities and 50\% index-linked government bonds, with annual rebalancing (and assuming that investment income received for each asset class is re-invested in the same asset class) so that the asset allocation strategy is static.

For the DAM case, in order to maintain a consistent level of investment return (with the SAM1 and SAM2 cases), we need to estimate the annual interest rate (assumed to be constant over the whole term) from a large number of trials based on the underlying stochastic asset model. This is obtained from running 1,000 simulations of the Wilkie model over an appropriate time horizon and calculating the equivalent mean annual compound rate of return. This method results in a constant rate of return of

$$
r=10.7 \% \mathrm{pa}
$$

for the first entry age (30) and minor adjustments have been made to allow for the effect of different entry ages used for later simulations.

\subsubsection{Inflation Rate Model}

Further volatility from the external economic environment is incorporated by allowing for the effects of random annual rates of inflation on the expenses (per unit of exposure) experienced in the portfolio and on the levels of premiums and benefits. For consistency with the stochastic investment return model, we apply the same type of first order autoregressive series model for the force of inflation as suggested in Wilkie (1995). However, we set different expected values (rather arbitrarily) for the time series. Thus, we assume a mean annual increase of $3 \%$ in the premium and benefits levels and a mean annual increase of $4 \%$ in the renewal and claim expenses, with corresponding variances 
determined by the simulations of the Wilkie model. We note that this configuration implies an indexed type of policy design (see section 3.1).

In summary, inflation has been incorporated within the three models as follows:

- For the DAM case, deterministic inflation rates are applied to the premium and benefit levels (at 3\% pa) and to the claim and renewal expense levels (at $4 \% \mathrm{pa}$ ). These are consistent with the predicted means of the formulated time series models.

- For the SAM1 case, deterministic inflation rates are applied to the premiums, benefits and expense levels (as above) but the investment returns are assumed to be stochastic (as described in section 3.3.1).

- For the SAM2 case, stochastic inflation rates are applied to the premiums, benefits and expense levels (with the investment returns also assumed to be stochastic).

\subsection{Cash Flow Model}

For any policy year $(t, t+1)$, the cash flow is assumed to occur mid-way through the year (for a mathematical treatment, that is equivalent to uniform incidence over a year) and is defined to be the difference between the simulated income and outgo i.e. for simulation $j$, the cash flow per cohort is:

$$
C F_{t}^{j}=P_{t}^{j}-C_{t}^{j}-\left(W_{t}^{j}+Y_{t}^{j}+Z_{t}^{j}\right)
$$

where for the policy year $(t, t+1)$ and simulation $j$ the components are:

$P_{t}^{j}=$ total premiums paid by all policyholders,

$C_{t}^{j}=$ total claim payments payable to policyholders who are sick and for whom the duration of sickness exceeds the deferred period of the policy,

$W_{t}^{j}=$ total premium-related expenses,

$Y_{t}^{j}=$ total regular claim expenses,

$Z_{t}^{j}=$ total initial claim expenses (payable at the commencement of a claim).

In equation (8), the terms $P_{t}^{j}$ and $W_{t}^{j}$ are proportional to the simulated time spent in the healthy state, or in the sick state if less than the deferred period. Similarly, the terms $C_{t}^{j}$ and $Y_{t}^{j}$ are proportional to the simulated time spent claiming (i.e. continuous sick time in excess of the deferred period) and finally, the term $Z_{t}^{j}$ is proportional to the simulated number of new claims initiated in year $(t, t+1)$.

In the above model, we assume an instantaneous occurrence of all cashflows so that there are no administrative (or other) delays. The policy funds then accumulate as follows:

$$
A_{t+1}^{j}=A_{t}^{j} \cdot\left(1+r_{t}^{j}\right)+C F_{t}^{j} \cdot\left(1+r_{t}^{j}\right)^{1 / 2}
$$


where $A_{t}^{j}$ represents the accumulated assets (in respect of all current policyholders) at time $t$ for simulation $j$ and $r_{t}^{j}$ is the simulated rate of return on investment for year $(t, t+1)$. In our calculations we assume that $A_{0}^{j}=0$ for all $j$ (i.e. there are zero initial assets per policy) apart from when we consider risk-based capital requirements in section 4.

For the case where rates of return on investment are assumed to be nonstochastic, $r_{t}^{j}$ is the estimated constant value referred to in section 3.3.1 (e.g. $r_{t}^{j}=10.7 \%$ for all $t$ and $j$ for entry age 30 ).

\subsection{Risk Measures}

We have considered four types of risk measures relevant to our model IP portfolio that we use in order to quantify the risks faced by an insurer with IP liabilities. These measures are defined as follows:

\section{Probability of Ruin}

This is evaluated as the proportion of outcomes with negative residual assets at the termination of the contract (i.e. $A_{m}<0$, where $m$ corresponds to the termination of the contract) from a predetermined number of sample simulations (with each simulation having an identical number of policies issued at entry age). That is:

$$
\operatorname{Pr}(\text { ruin })=\frac{k}{N}
$$

where $k$ represents the number of insolvent cases and $N$ is the total number of simulations (usually 500). Note that the actual size of the ruin is irrelevant for this risk measure.

\section{Mean Shortfall}

The mean shortfall is the mean of $A_{m}$ (the residual assets at the termination of the contract), conditional on $A_{m}<0$. This is estimated by the average shortfall in a predetermined number of simulations $(N)$ relative to the (fixed) number of policies at entry:

$$
\text { ruin }_{r e l}=\frac{1}{n}\left[\frac{1}{k} \sum_{j=1}^{k} A_{m}^{j}\right] \text { where } A_{m}^{j}<0 \text { for } j=1, k
$$

$n$ is the number of policies issued at $x_{1}$ (constant across the trials) and $k$ is the number of insolvent cases. To facilitate comparison between cohorts of different sizes, we express this index relative to $n$.

Although it is theoretically possible to have a simulation $j$ such that $A_{t}^{j}<0$ for some $t<m$ but $A_{m}^{j} \geq 0$, this situation does not in fact arise for any of our simulations. 
As demonstrated by Artzner et al (1997) and Artzner (1999), risk measures based on the mean shortfall approach are superior to the more commonly used Value-at-Risk (VAR) measures. In particular, they satisfy the coherence requirement by being sub-additive (whereas VAR measures need not satisfy this property) and are less sensitive to changes in the tail of the distribution being investigated.

\section{Risk-Based Capital}

The amount of capital (i.e. assets) required at outset $A_{0}(\varepsilon)$ in order to secure at most a pre-specified probability of ruin $\varepsilon$ (assuming a 'break-even' premium level, see section 3.6). Note that this is expressed in multiples of the break-even premium.

\section{Risk-Loaded Premium}

The percentage of additional premium $\lambda(\varepsilon)$ (to be added to the 'break-even' premium, see section 3.6) required to secure at most a pre-specified probability of ruin $\varepsilon$.

\subsection{Calculation of the "Break-Even" Premium}

In order to calculate the "break-even" initial premium per policy for a particular class of models (i.e. DAM, SAM1 or SAM2), we consider a portfolio of 1,000 identical policies and run $N=500$ simulations of the residual policy funds at the termination of the contracts (i.e. at age 65) for a given initial premium. We then use iteration to derive a value for the initial premium such that

$$
\operatorname{Pr}(\text { ruin })=0.5
$$

where $\operatorname{Pr}($ ruin) is the probability of ruin defined in section 3.5.

The values that are obtained (rounded to the nearest pound) for the different entry ages under consideration are summarised in the following table:

TABLE 2

SUMMARY OF BREAK-EVEN INITIAL PREMIUMS

\begin{tabular}{|c|c|c|}
\hline \multirow{2}{*}{$\begin{array}{c}\text { Age at } \\
\text { Entry }\end{array}$} & \multicolumn{2}{|c|}{ Break-even Initial Premium (£) } \\
\hline & SAM1 (DAM) & SAM2 \\
\hline 30 & 220 & 235 \\
\hline 40 & 272 & 280 \\
\hline 50 & 336 & 338 \\
\hline 60 & 462 & 462 \\
\hline
\end{tabular}


The models DAM and SAM1 lead, not unexpectedly, to almost identical breakeven premiums for the 1,000 policies at issue, and continue to be close even for significant changes in the size of the initial cohort (see Figure 11, later). We recall that the SAM1 approach uses simulated annual investment returns while the DAM approach uses an equivalent mean annual compound rate of return. However, there is an increase (about 7\% for entry age 30, see Figure 12, later) in the break-even premium level when we move from the SAM1 to the SAM2 model. This arises because the SAM2 approach includes an extra level of variability compared to the SAM1 approach through the impact of stochastic inflation on premiums, benefits and expenses. This effect becomes less significant with increases in the entry age (i.e. as the insurance term reduces) due to the reduction in the cumulative effect of the stochastic components.

This approach is different from the conventional approach based on the equivalence principle where we equate expected present values of policy income and outgo. In future work, we will investigate the effect of different choices for the calculation method for the premium.

The implications of using (10) are that:

a) the premium does not include any margin for profit or adverse experience,

b) the company expects to "break even" at the termination of the contracts, assuming that all profits are retained internally and

c) any projection that leads to ruin (of the portfolio) can be attributed to "process error" only.

\section{Simulation Results}

Because of the limited space available, we will present only a selection of the results. A fuller set of results is provided in an accompanying working paper: Haberman et al (2001).

Figures 4 to 6 show the simulated distribution of the assets for a portfolio of $n$ policies issued at age 30 for the respective cases $n=1,000$ and 10,000, based on 500 simulations. These figures summarise the distribution at each age through the use of box-plots with the $25^{\text {th }}, 50^{\text {th }}$ and $75^{\text {th }}$ percentiles clearly identified. Figure 4 is based on the DAM asset model i.e. random morbidity and deterministic economic variables. It is clear that as $n$ increases, the distributions become more compact, showing that the demographic process risk is reduced by the pooling of policies as discussed in section 1 .

Figures 5 and 6 repeat the presentation but allow for stochastic investment returns and inflation, based on the SAM1 and SAM2 approaches, respectively. Generally the distributions in Figures 5 and 6 are much wider than in Figure 4 as we would anticipate because of the extra source of variability present. Also, the more randomness that is built into the models the larger is the variance across the ages. However, there is an important feature that can be observed: while in the SAM1 type the pooling effect is still present, although reduced compared to DAM (i.e. the variability reduces with the size of the portfolio), in the case of SAM2 the effect is much less apparent. This would suggest that 

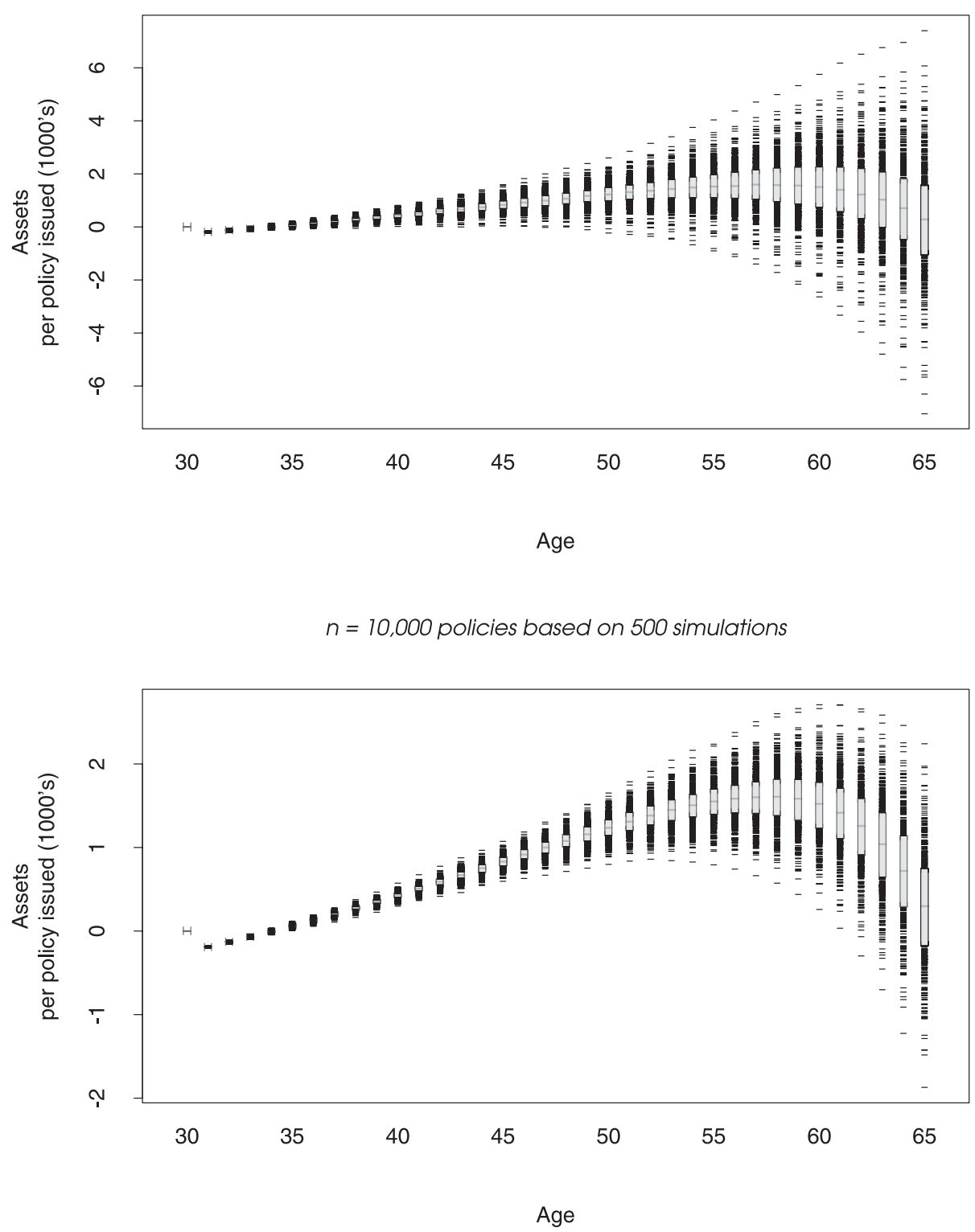

FIGURE 4: Deterministic Assets Distribution over age for 1,000 and 10,000 policies at outset.

the additional process risk introduced in the SAM2 model by assuming that the inflation rates applied to the premiums, benefits and expenses are stochastic is far more important than the process risk inherent in the morbidity part of the model. 


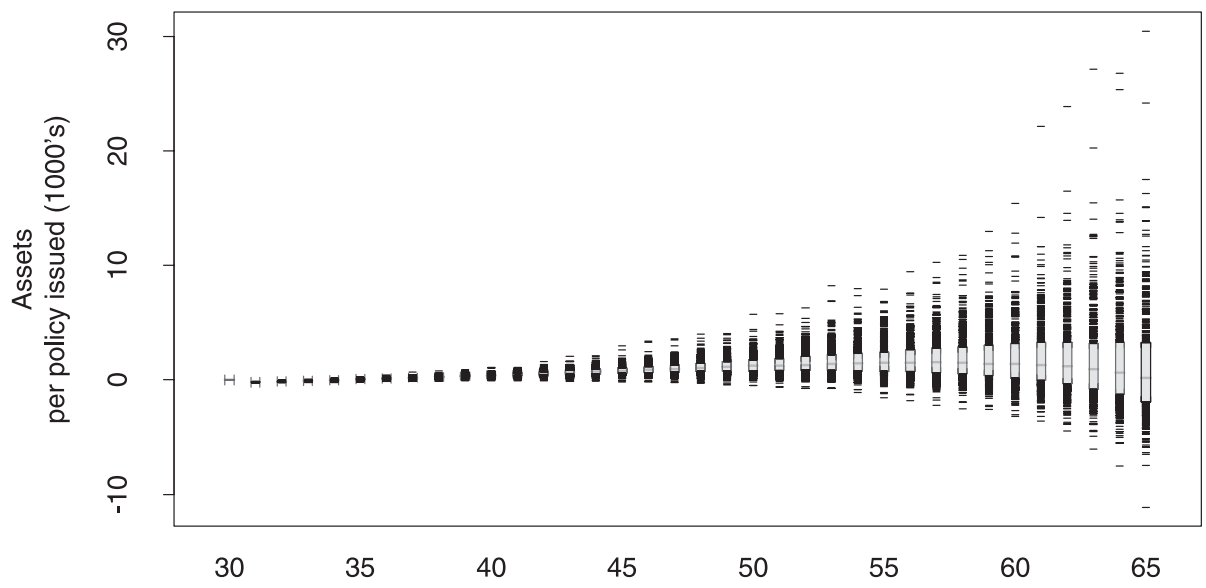

Age

$n=10,000$ policies based on 500 simulations

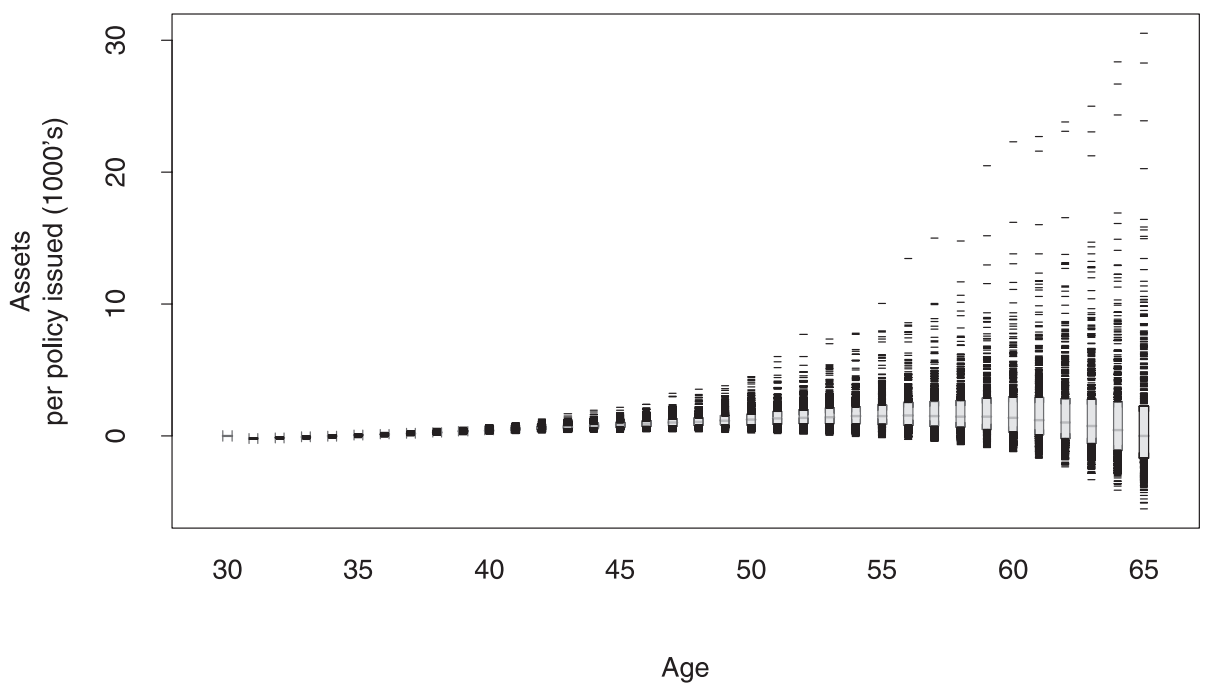

FIgURE 5: Stochastic Assets Distribution (SAM1) over age for 1,000 and 10,000 policies at outset.

Surprisingly, in the SAM2 case the sample standard deviation of the residual funds increases in size when we move from 1,000 to 10,000 policies assumed at entry age. However, it should be stressed that the increase seems to be due mainly to a small number of extreme cases (i.e. outliers) and the 


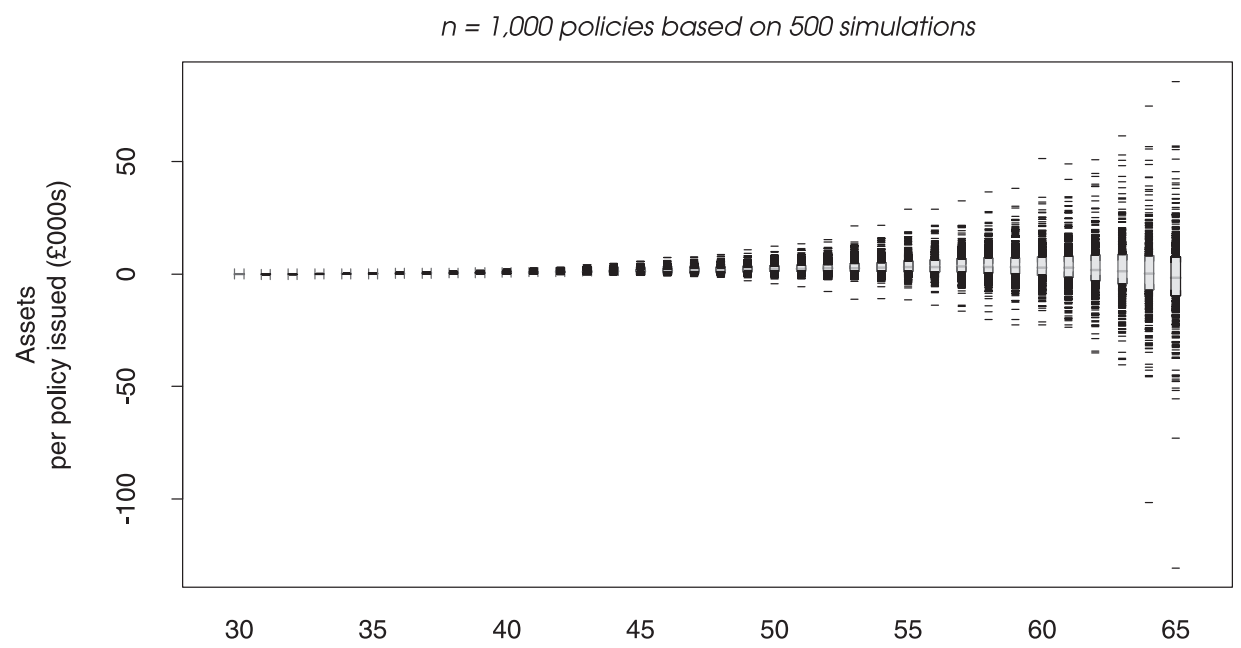

Age



FIGURE 6: Stochastic Assets Distribution (SAM2) over age for 1,000 and 10,000 policies at outset.

resulting sample distribution of the residual assets for the case of 10,000 policies at entry is, in fact, more peaked at the mean than the one corresponding to the portfolio with 1,000 policies at entry. Indeed, this effect is reduced for the SAM2 model, when the number of simulations is increased to 1,000 and beyond. 
Figures 7 and 8 illustrate the simulated distributions of the residual assets for portfolios of lives with initial ages 30 and 60, respectively, for the SAM1 case with the rates of investment returns generated from the Wilkie model as described earlier. Similarly Figures 9 and 10 represent the simulated distributions for the DAM and SAM2 cases, respectively, with entry age 30 . The following features are noteworthy.

a) increasing the portfolio size from $n=1,000$ to $n=10,000$, when the asset model is deterministic, leads to a reduction in the standard deviation of the residual assets by a factor of approximately $\sqrt{10}$ (as we would expect from the pooling of risks), so that the distribution is sharper (see Figure 9);

b) the feature described in a) above whereby the standard deviation of the residual assets reduces as the portfolio size increases is not as pronounced in the stochastic model SAM1 (see Figures 7 and 8). This is because the pooling of risks does not reduce the impact of investment return variability which affects all policies in the portfolio simultaneously. However, with the reduction of the policy term (as we move from Figure 7 to 8 ) the effect of pooling of risks increases in weight and the reduction in the standard deviation from a portfolio size of $n=1,000$ to $n=10,000$ is much more significant. Indeed, the reduction factor approaches $\sqrt{10}$ as the entry age increases from 30 to 60 ;

c) furthermore, in the case of the 'fully-stochastic' model, SAM2, shown in Figure 10, the level of the uncertainty of the outcome is less dependent on the size of the portfolio, and it is possible that increasing the number of policies could increase the process risk;

d) increasing the policy term (i.e. reducing the age at entry) leads to an increase in the skewness of the distribution. This is because the accumulation effect becomes stronger for longer terms and corresponds to the approximate lognormal character of the simulated accumulations obtained from the Wilkie model (see Figures 7 and 8);

e) in the SAM2 case, the shape of the distribution is normal rather than lognormal (see Figure 10).

The implication of changing the entry ages $(30,40,50$ and 60$)$ on the residual assets (and on the probability of ruin) across the defined models is summarised in more detail in Table 3 for the $n=1,000$ and $n=10,000$ portfolios. We note that the ratios of the standard deviations of the residual assets for the SAM1 and SAM2 cases relative to the DAM case are inversely related to the initial policy term (i.e. 65 minus entry age). Thus, with a sufficiently short initial policy term (i.e. high entry age) this ratio reduces to 1 . For example, for an entry age of 30 the standard deviation of the residual assets for SAM2 is 9.4 times as large as for DAM and for SAM1 is 2.3 times as large as for DAM (for the case of $n=1,000$ ). But for an entry age of 60 , the relative ratios are both close to 1 , demonstrating very similar process risks for the three models in this case.

We now consider the effects of changing the initial assets and the initial premium per policy on the first two defined risk measures (i.e. probability of ruin and mean shortfall). For the case of a portfolio of policies with age at entry 30 and $n=10,000$, Figure 11 shows the effect on the probability of ruin of increasing 


\section{1,000 policies}

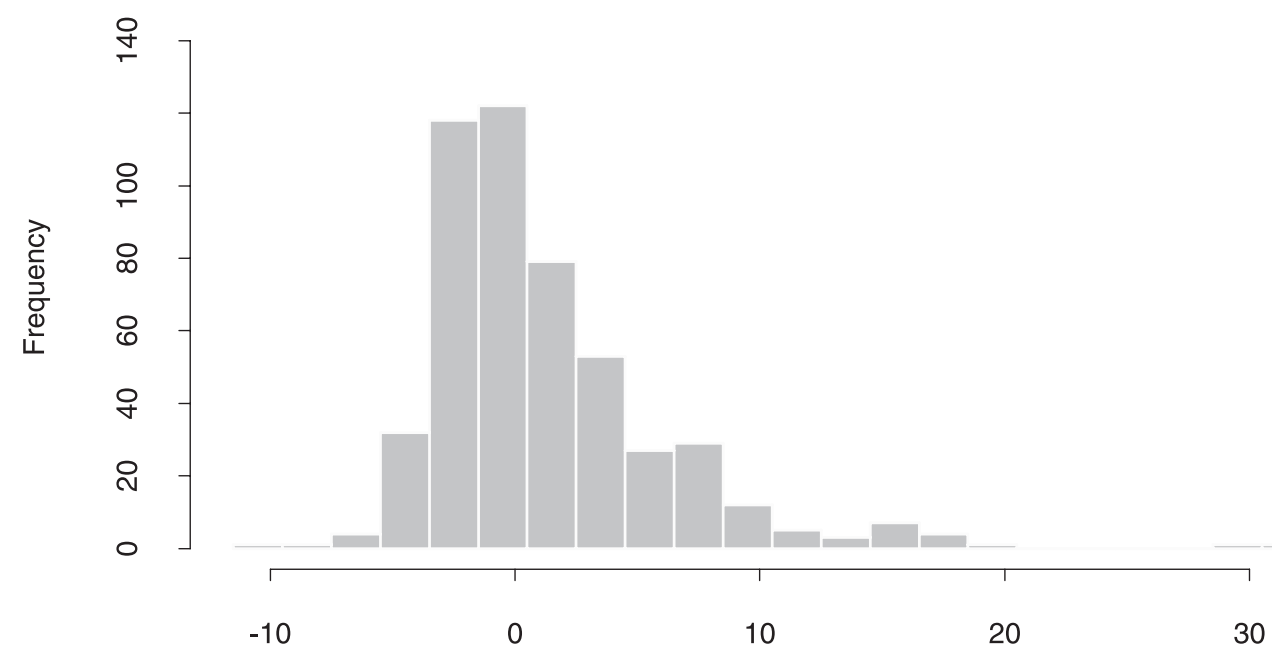

Assets $(\mathrm{x} 1000)$ per policy issued

10,000 policies
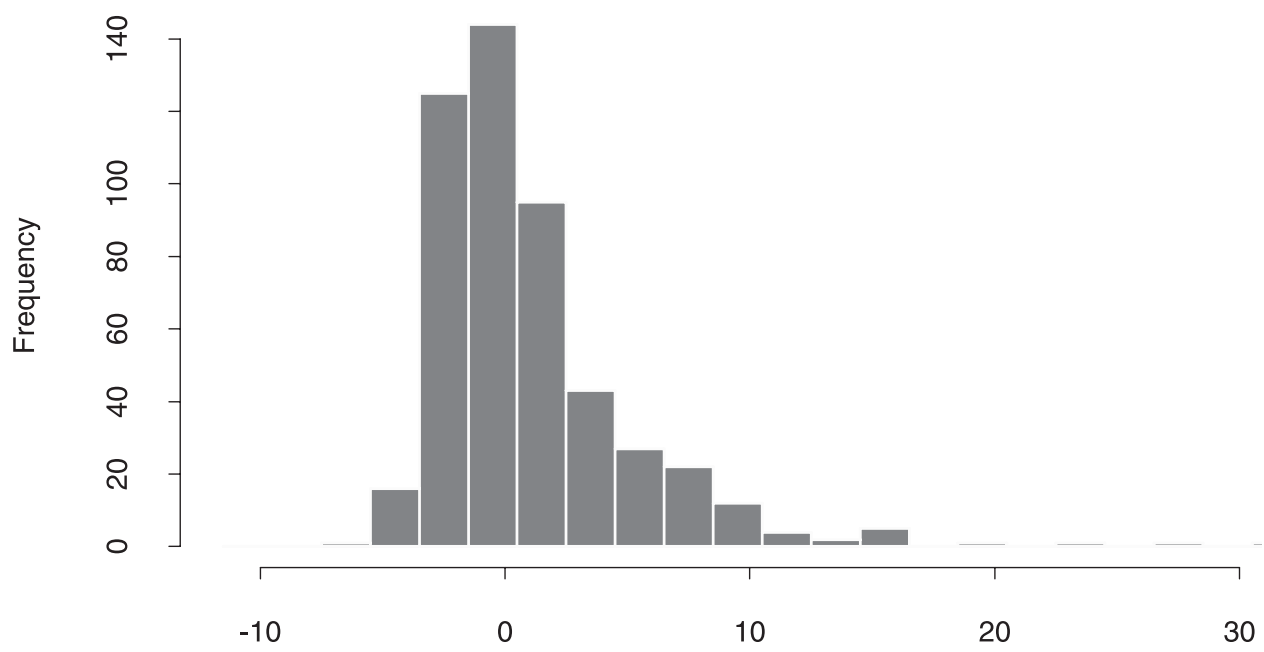

Assets (x1000) per policy issued

Figure 7: SAM1 Residual Assets Distribution in relation to entry age 30. 


\section{1,000 policies}

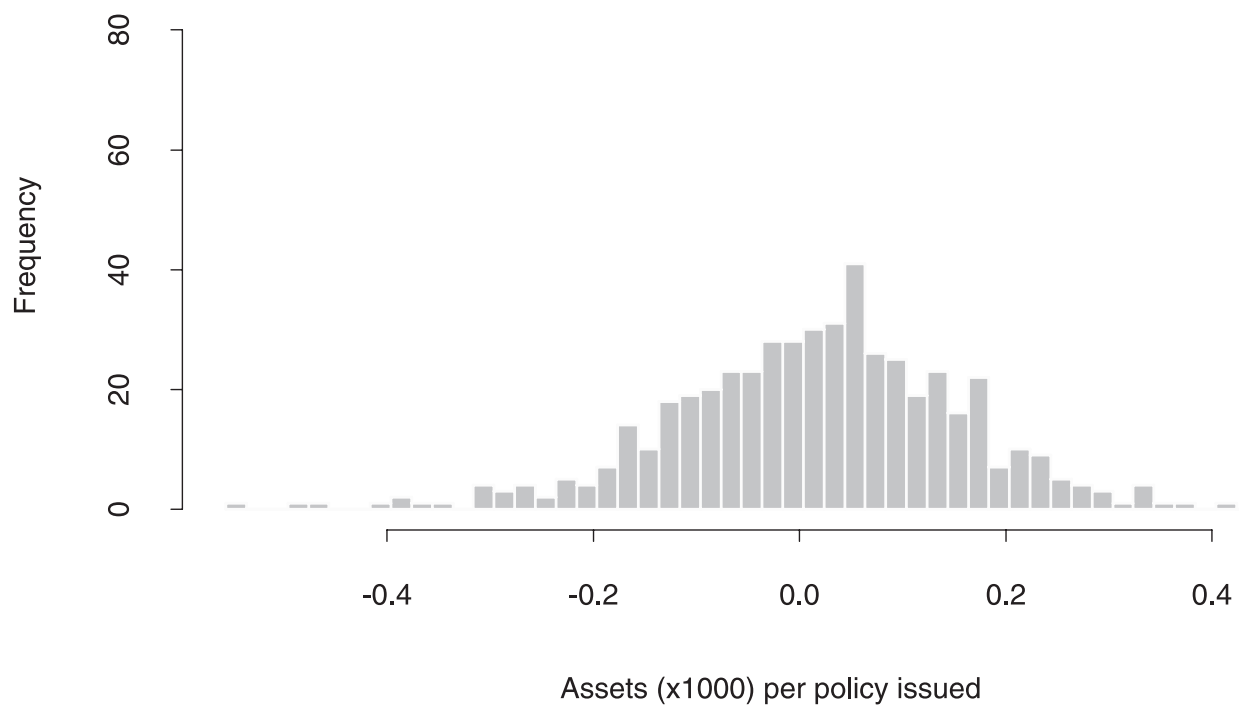

10,000 policies
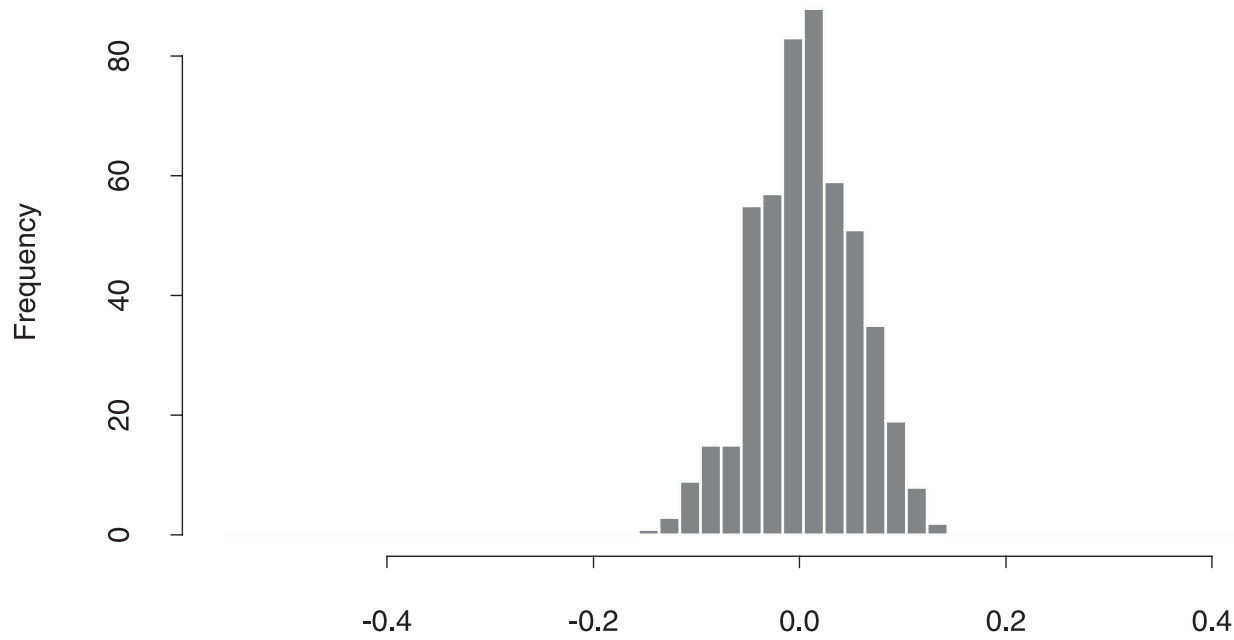

Assets (x1000) per policy issued

FIgURE 8: SAM1 Residual Assets Distribution in relation to entry age 60. 
TABLE 3

Residual Assets Distribution and Probability of Ruin for VARIOUs COHORTS

\begin{tabular}{|c|c|c|c|c|c|c|c|c|c|}
\hline $\begin{array}{l}\text { Entry } \\
\text { Age }\end{array}$ & \multicolumn{3}{|c|}{$\begin{array}{c}\text { Mean of Assets } \\
(£ 000 s) \text { per policy issued }\end{array}$} & \multicolumn{3}{|c|}{$\begin{array}{l}\text { Standard Deviation of Assets } \\
(£ 000 \text { s) per policy issued }\end{array}$} & \multicolumn{3}{|c|}{$\begin{array}{c}\text { Probability of Ruin } \\
\qquad(\%)\end{array}$} \\
\hline \multirow{2}{*}{$x_{1}$} & \multicolumn{9}{|c|}{1,000 policies issued at entry age } \\
\hline & SAM2 & SAM1 & DAM & SAM2 & SAM1 & DAM & SAM2 & SAM1 & DAM \\
\hline 30 & -1.711 & 1.171 & 0.204 & 19.369 & 4.825 & 2.065 & 53.7 & 51.0 & 47.0 \\
\hline 40 & 0.012 & 0.303 & 0.103 & 3.979 & 1.490 & 0.845 & 50.3 & 49.8 & 45.8 \\
\hline 50 & -0.005 & 0.000 & -1.985 & 0.732 & 0.471 & 0.411 & 51.7 & 50.0 & 49.2 \\
\hline \multirow[t]{2}{*}{60} & 0.003 & 0.016 & 0.016 & 0.147 & 0.141 & 0.137 & 49.5 & 42.4 & 42.2 \\
\hline & \multicolumn{9}{|c|}{10,000 policies issued at entry age } \\
\hline 30 & -2.355 & 1.052 & 0.273 & 20.119 & 4.296 & 0.644 & 53.0 & 50.0 & 33.0 \\
\hline 40 & 0.016 & 0.187 & 0.078 & 3.502 & 1.044 & 0.296 & 53.1 & 51.2 & 38.0 \\
\hline 50 & -0.021 & 0.073 & 0.032 & 0.567 & 0.231 & 0.121 & 52.5 & 43.6 & 37.8 \\
\hline 60 & 0.002 & 0.007 & 0.008 & 0.063 & 0.049 & 0.045 & 49.4 & 44.6 & 43.6 \\
\hline
\end{tabular}

the initial assets from zero in the upper panel and the effect of charging an initial premium which is different from the break-even premium of $£ 220$ in the lower panel. In each case, the curves of the probability of ruin for the stochastic model, SAM1, and for the model with deterministic asset returns, DAM, are presented. We note the following features:

a) from the upper panel, initial assets of zero correspond approximately to a probability of ruin of 0.5 for the stochastic case (and to a slightly lower level for the deterministic case because of there being fewer unfavourable results within the 500 simulations for the DAM model - this effect disappears when we increase the number of simulations);

b) increasing the initial assets per policy leads to a lower probability of ruin. This is more marked for the deterministic case where there is less overall variability;

c) from the lower panel, an initial premium of $£ 220$ corresponds approximately to a probability of ruin of 0.5 ;

d) increasing the premium beyond $£ 220$ leads to a lower probability of ruin, which, as in b), is more marked for the deterministic case;

e) decreasing the premium below $£ 220$ leads to a higher probability of ruin and we note that, unlike d), the extra variability from the stochastic case (SAM1) may help when the premium is inadequate and may lead to a lower probability of ruin.

We note that the variation of the probability of ruin when considered as a function of either the initial assets or the initial premium is amplified in the case of a smaller portfolio (results not shown). For the deterministic model 


\section{1,000 policies}

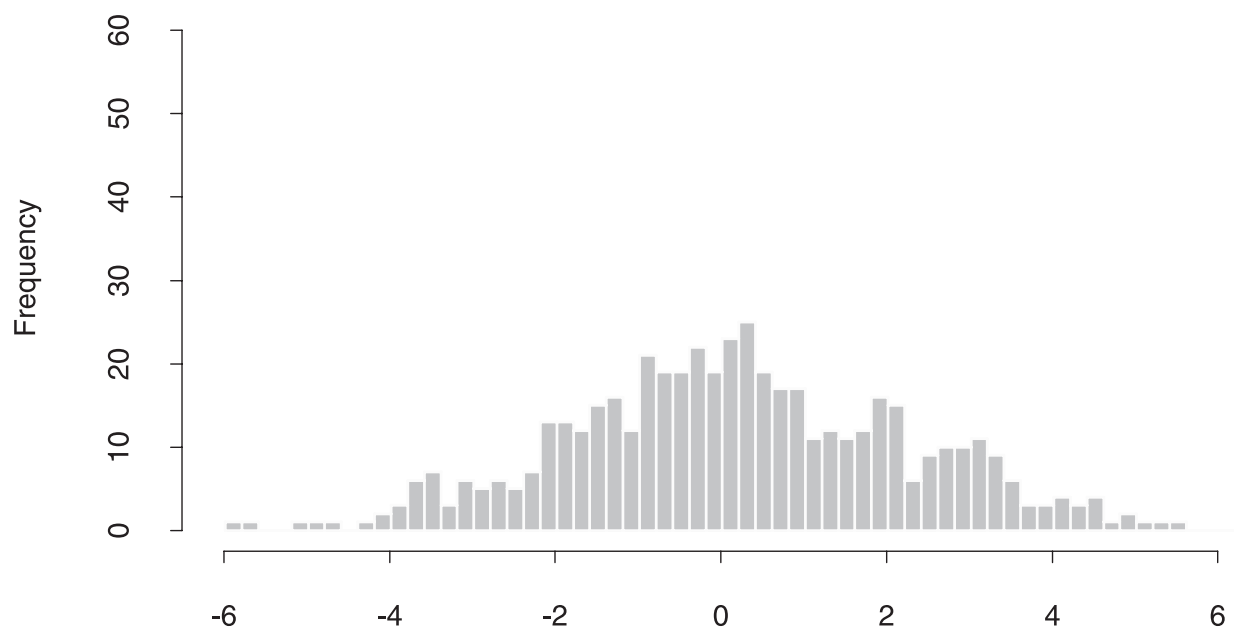

Assets $(x 1000)$ per policy issued

10,000 policies

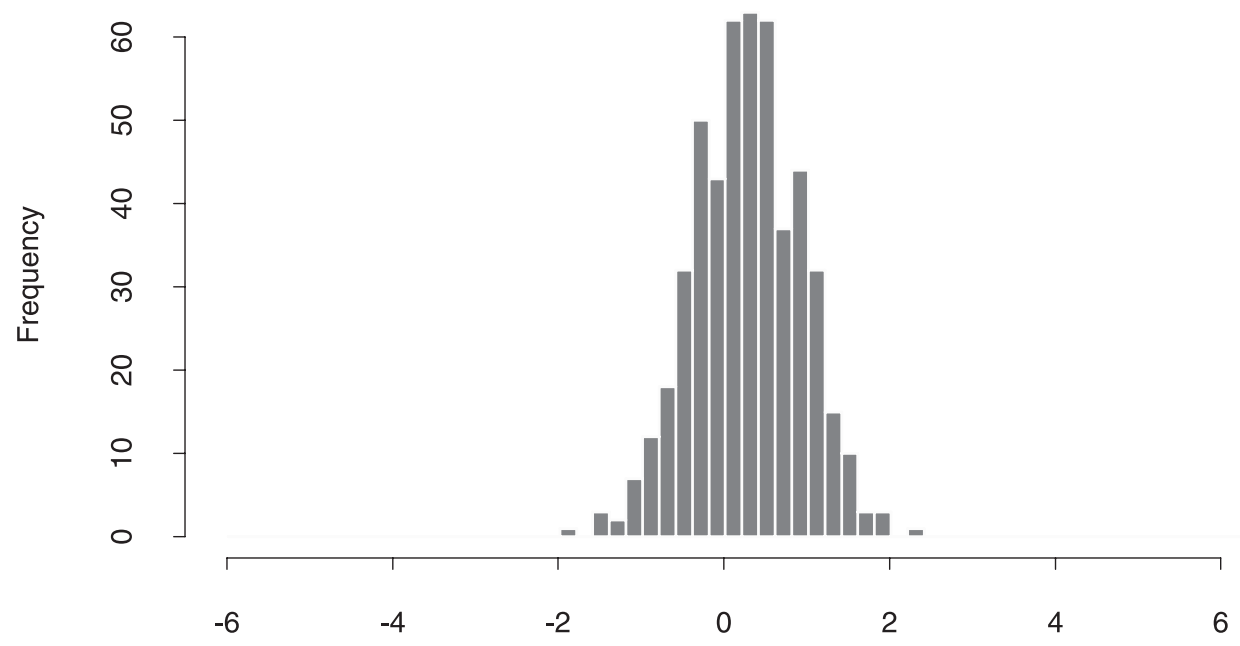

Assets $(x 1000)$ per policy issued

FIgURE 9: DAM Residual Assets Distribution in relation to entry age 30. 


\section{1,000 entry policies}

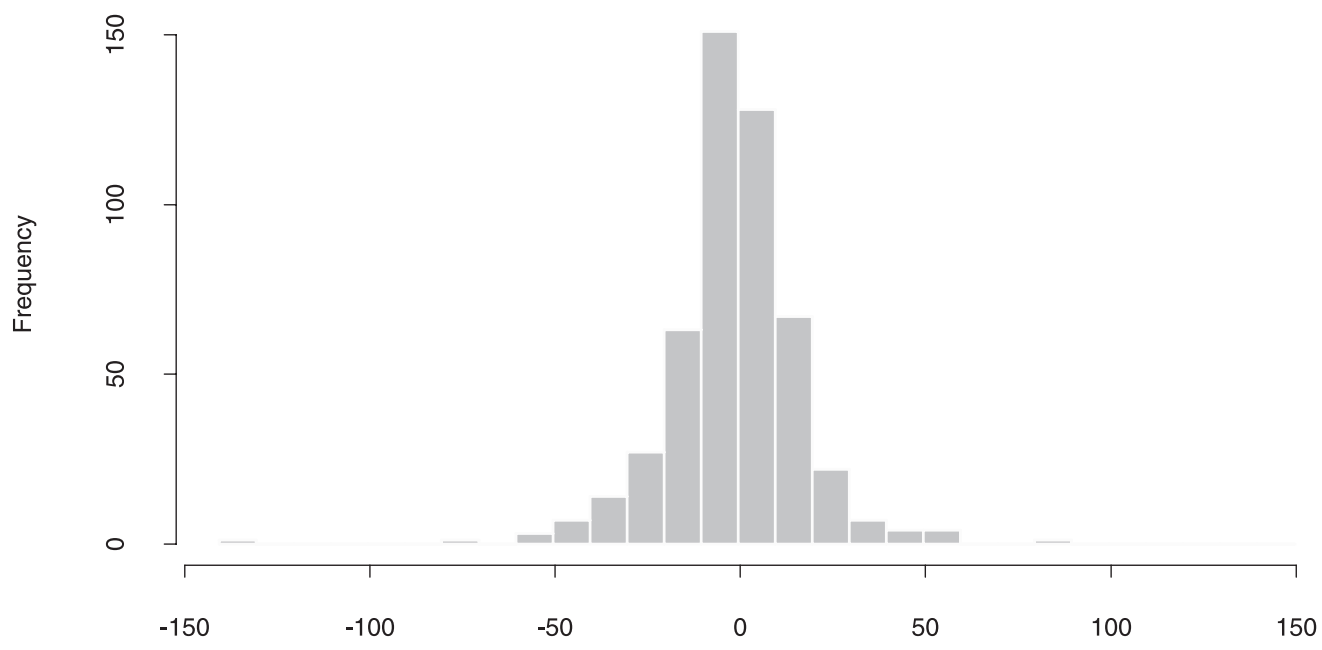

Assets (£000s) per policy issued

10,000 entry policies

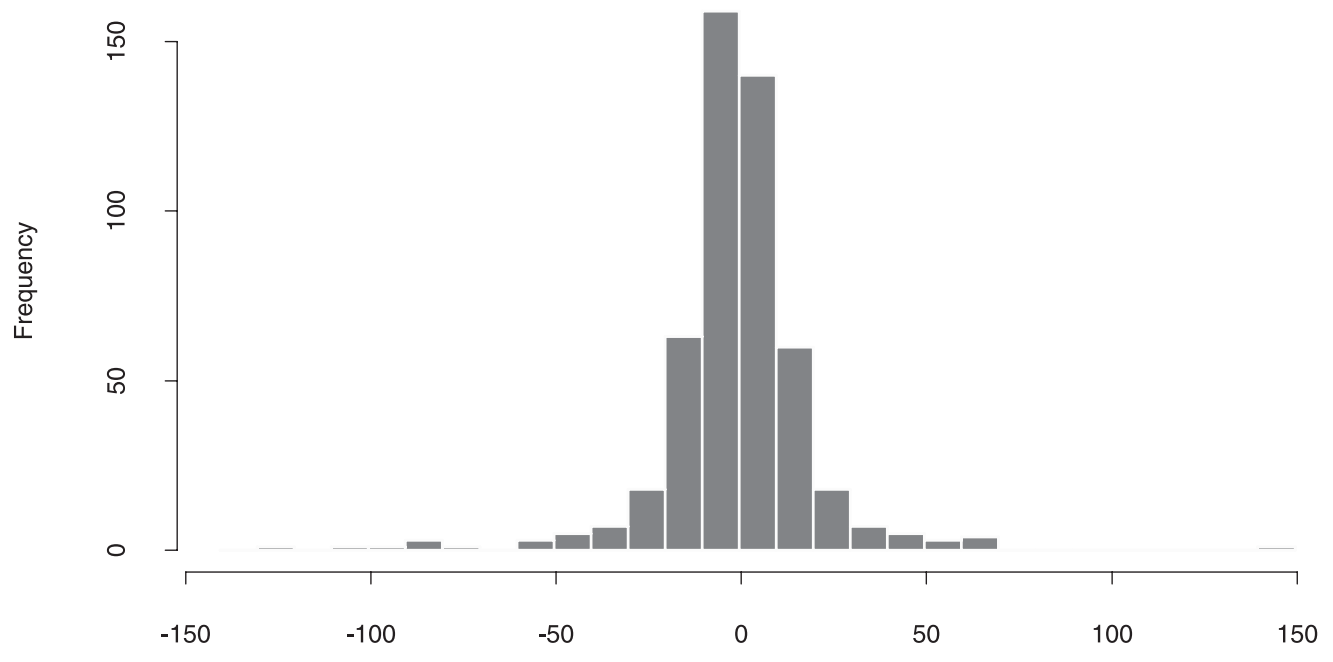

Assets (£000s) per policy issued

FIgURE 10: SAM2 Residual Assets Distribution in relation to entry age 30. 
(DAM), this is particularly dramatic, for example with the tenfold decrease in portfolio size leading to a significant increase in "process risk" and a considerable degree of fluctuation in the curves corresponding to Figure 11, for the case of $n=1,000$ policies (results not shown).

Figures 12 and 13 allow us to compare the probability of ruin and mean shortfall profiles in the case of the different modelling frameworks for a portfolio with $n=10,000$. From Figure 12, which compares the SAM1 and SAM2 models, we note that an increase in the size of the break-even premium (calculated as described in section 3.6) is required for the SAM2 model, due to the extra variability present in the latter. We observe that, overall, the slopes of the curves decrease with an increase in the volatility in the models, so that, the more volatility that is allowed for in the model, the greater is the increase in the initial premium (or assets) needed to achieve a given reduction in the probability of ruin. This is demonstrated in Table 4, where we can see that in order to reduce the probability of ruin from $25 \%$ to, say, $5 \%$, the SAM 2 model requires a significantly higher capital input than the SAM1, or indeed the DAM, models. Similarly, Table 5 shows a substantial increase in the additional premium required in the first year to produce the same probability of ruin $(5 \%)$ in the SAM1 and SAM2 models.

Figure 13 compares the mean shortfall by annual premium for the DAM and SAM2 models. We note that, for both models, increasing the annual premium leads to a reduction in the size of the mean shortfall, as expected. The mean shortfall is larger in size for the SAM2 case than the DAM case as before, a reflection of the inclusion of process risk from the economic variables. We note the smooth progression in the curve for the DAM case. For the SAM2 case, the mean shortfalls are more erratic as the annual premium is increased. This arises because the number of simulations with $A_{m}<0$ reduces as the annual premium is increased and so this feature is a reflection of sampling error - and we have fitted a smoothing curve in an attempt to reduce the impact of this variation. ${ }^{1}$ It is interesting to note that there is a steady decrease in the mean shortfall as the initial premium is increased up to the break-even level for both models. The smoothing curve indicates that this trend continues as the premium is increased further, although, as noted above, there is increased variability in the underlying estimates.

We recall that $A_{0}(\varepsilon)$ is the level of initial assets required to produce at most a given level of probability of ruin $(\varepsilon)$. We now consider Table 4 in more detail which presents some examples of $A_{0}(\varepsilon)$, calculated relative to the annual premium in the first year of the policy, for the cases of $n=1,000$ and 10,000 for the deterministic and stochastic asset models and a range of values of $\varepsilon$. We note that, in the case of the stochastic models, the values in the tables have been determined based on the smoothed probability curves mentioned earlier. The results show that:

a) reducing $\varepsilon$ leads to an increase in $A_{0}(\varepsilon)$, as expected;

\footnotetext{
1 We have used a robust local smooth curve generated using the 'lowess' S-Plus smoothing routine, which, in effect, estimates each point of the curve by robust local linear fits from a given (local) proportion of the total observations (see Venables and Ripley, 1999).
} 

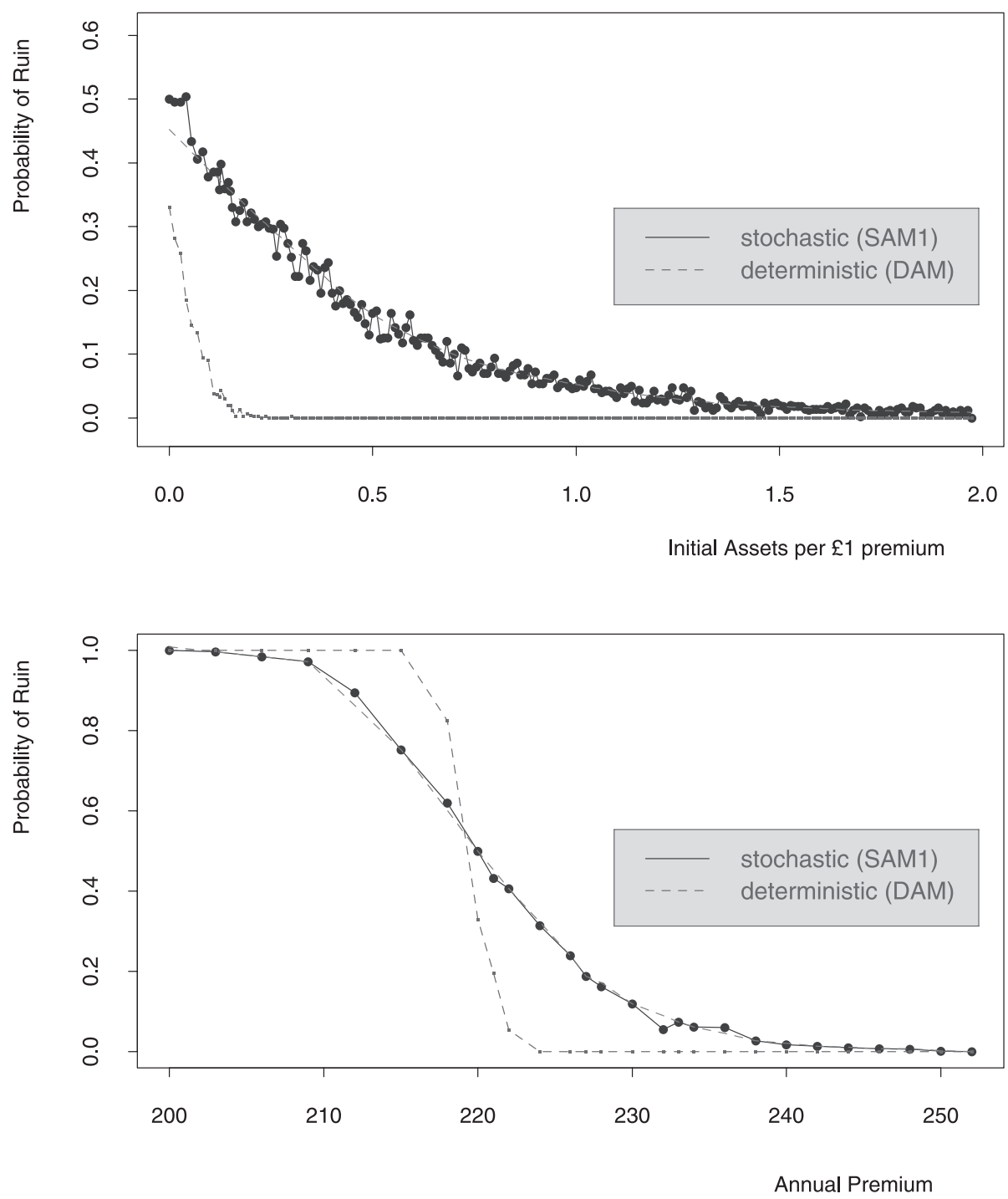

FIGURE 11: Probability of Ruin by initial assets and premium level for SAM1 and DAM in relation to 10,000 policies assumed at outset.

b) for the deterministic asset model, DAM, increasing $n$ has a significant effect on $A_{0}(\varepsilon)$, indicating the extent to which the demographic process risk reduces as the portfolio size increases;

c) for the stochastic asset models, the effect of increasing $n$ has a much weaker effect on $A_{0}(\varepsilon)$. This indicates that the demographic process risk identified in b) is relatively insignificant when compared with the process risk arising from the economic variables. 


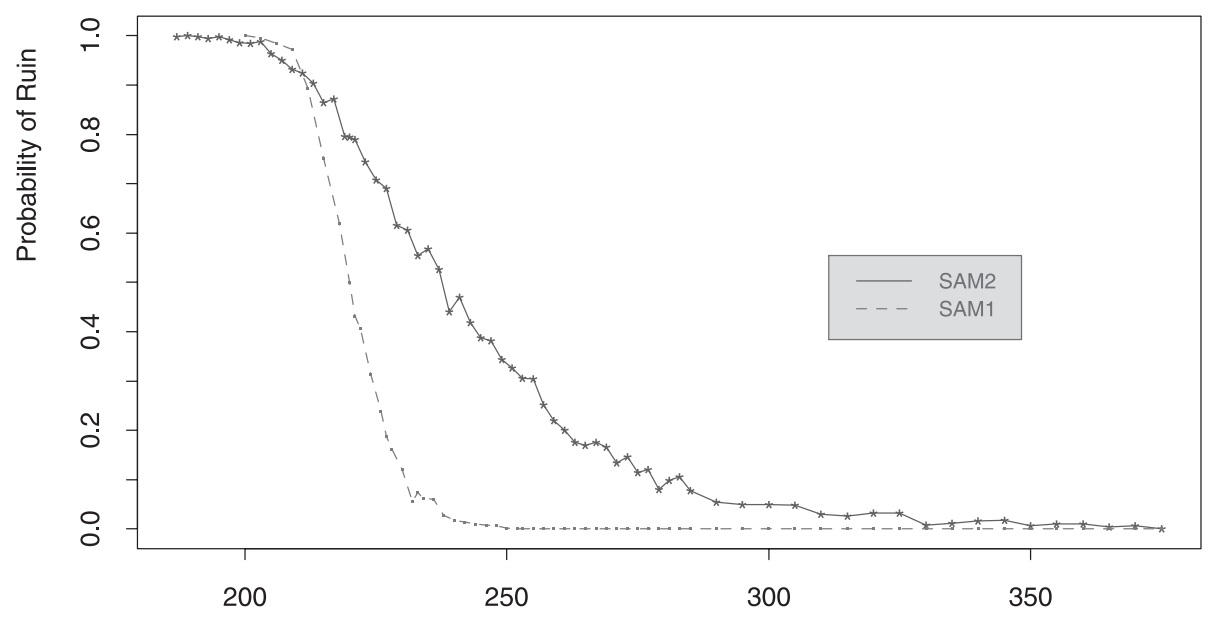

Annual Premium

FIGURE 12: Probability of Ruin against premium level for SAM1 and SAM2 models in relation to 10,000 policies assumed at outset.

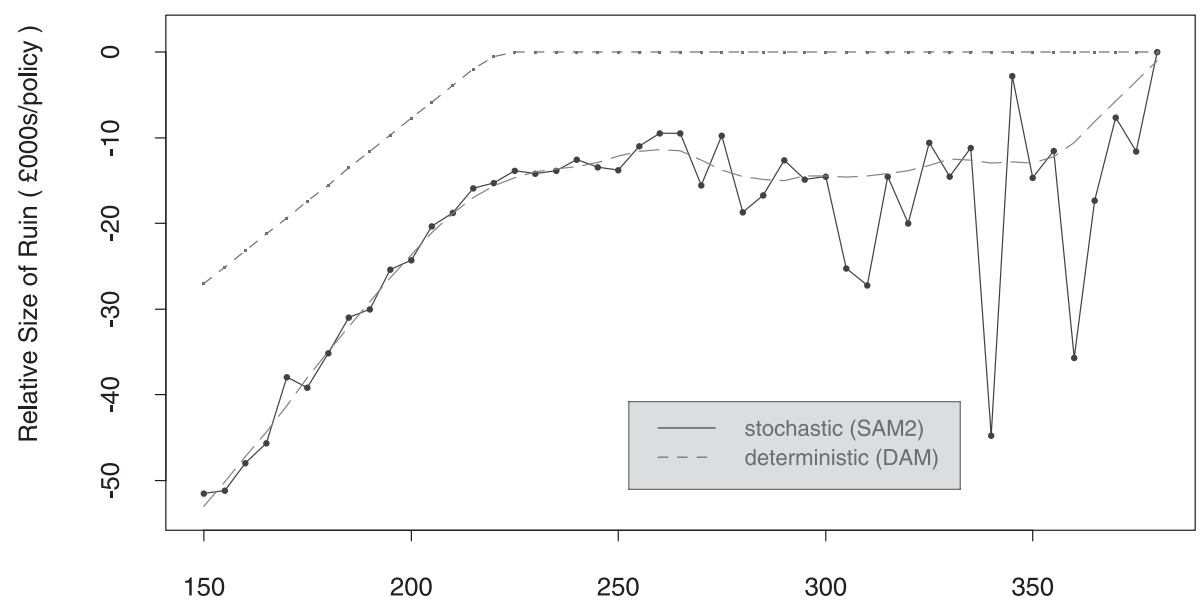

Annual Premium

FIGURE 13: Average relative size of insolvency against premium level for SAM2 and DAM models in relation to 10,000 policies assumed at outset.

Table 5 presents the results for $A_{0}(\varepsilon)=0$ for $\varepsilon=10 \%, 5 \%$ and $1 \%$ but allowing a proportionate risk loading $1+\lambda(\varepsilon)$ to the premiums (i.e. the percentage increase in the initial premium required to obtain a maximum probability of ruin of $\varepsilon^{0} \%$ when there are no initial assets per policy). Similar effects are demonstrated. 
TABLE 4

Risk-BASEd CAPITAL AT ENTRY AGE 30 - INITIAL ASSETS (£000s) REQUIRED TO PRODUCE A GIVEN RUIN PROBABILITY (PER $£ 1$ ANNUAL PREMIUM IN YEAR 1 )*

\begin{tabular}{ccc|cccc}
\hline \hline & \multirow{2}{*}{\begin{tabular}{c}
\multirow{2}{*}{ Deterministic Asset Model } \\
DAM
\end{tabular}} & \multicolumn{4}{c}{ Stochastic Asset Models } \\
& DAM & SAM1 & SAM1 & SAM2 & SAM2 \\
\hline $\operatorname{Pr}$ (Ruin) & $n=1,000$ & $n=10,000$ & $n=1,000$ & $n=10,000$ & $n=1,000$ & $n=10,000$ \\
\hline $25 \%$ & 0.148 & 0.025 & 0.366 & 0.329 & 1.609 & 1.398 \\
$10 \%$ & 0.305 & 0.081 & 0.787 & 0.697 & 3.545 & 3.471 \\
$5 \%$ & 0.402 & 0.101 & 1.173 & 1.020 & 5.515 & 5.737 \\
$1 \%$ & 0.534 & 0.162 & 2.022 & 1.856 & 13.551 & 12.556 \\
\hline \hline
\end{tabular}

* where 0 initial assets produce a $50 \%$ probability of ruin for the break-even initial premiums defined in Table 2.

TABLE 5

Risk-LoAded Premium at ENTRY Age 30 - AdDITIONAl PREMIUM REQUiRED IN YeAR 1 TO PRODUCE AN $\varepsilon \%$ RUIN PROBABILITY ASSUMING 0 INITIAL ASSETS

\begin{tabular}{rcc|cccc}
\hline \hline & \multirow{2}{*}{$\begin{array}{c}\text { Deterministic Asset Model } \\
\text { DAM }\end{array}$} & \multicolumn{4}{|c}{ Stochastic Asset Models } \\
& DAM & SAM1 & SAM1 & SAM2 & SAM2 \\
\hline \multirow{2}{*}{$\varepsilon$} & $n=1,000$ & $n=10,000$ & $n=1,000$ & $n=10,000$ & $n=1,000$ & $n=10,000$ \\
\hline $10 \%$ & $2.9 \%$ & $0.8 \%$ & $6.0 \%$ & $5.1 \%$ & $20.1 \%$ & $19.5 \%$ \\
$5 \%$ & $3.5 \%$ & $1.0 \%$ & $7.9 \%$ & $7.0 \%$ & $29.0 \%$ & $27.9 \%$ \\
$1 \%$ & $5.4 \%$ & $1.6 \%$ & $11.8 \%$ & $11.5 \%$ & $51.8 \%$ & $50.1 \%$ \\
\hline \hline
\end{tabular}

\section{Conclusions}

The results presented here (and more extensive investigations not reported) demonstrate that pooling, as implied by the law of large numbers, reduces the demographic process error. We have shown that the economic process error is considerably more significant than the demographic process error for portfolios of income protection insurance policies. We have also shown that the length of term has a decisive influence on the weight of these components of the process risk. Therefore, the shorter the policy term the more the process risk depends on the experienced morbidity and on the size of the portfolio, so that the insurer is relatively more vulnerable to the morbidity experience.

We have demonstrated the methodology for simulating asset/liability profiles in a multiple state context and shown how estimates for risk-loaded premiums and for risk-based capital can be obtained. We have also shown, from the simulation results, the extent to which the risk measures investigated depend on the input parameters (in particular, the level of the initial premium or of the initial capital) for models with different levels of stochasticity. 
We have conducted some trials based on changing various aspects of the model, for example the parameterization of the transition intensities, $\mu_{x}^{12}$ and $\mu_{x}^{21}$, as in (3) and (5) and the choice of the deferred period in the policy design. These results indicate that the principal conclusions remain valid.

We have investigated a simple policy design. More complex features that could be added would include:

a) lapse rates, possibly dependent on the type of business;

b) effects of policy duration and temporary initial selection;

c) more complex benefit schemes, for example split levels of benefits as in Long Term Care contracts and inclusion of termination and death benefits;

d) reviewable premiums, where the level of premium depends on the recent claims experience at the portfolio level.

As an extension to this study, we are conducting a systematic sensitivity analysis of the results to changes in the transition intensities.

\section{AcKnowledgements}

The authors would like to acknowledge financial support (for Zoltan Butt) from the Faculty and Institute of Actuaries' Research Committee and CMI Bureau which helped to bring this work to fruition.

An earlier version of this paper was presented to the Institute and Faculty of Actuaries' Health Care Convention in Torquay in 2000 and to the $31^{\text {st }}$ ASTIN Colloquium in Porto Cervo, Sardinia in 2000. The authors would like to thank several participants for their insightful comments, in particular Hans Buhlmann, Paul Embrechts and Ermanno Pitacco. The authors would like also to thank the anonymous referees for their helpful suggestions, which led to improvements to the paper.

\section{REFERENCES}

ARTZNER, P. (1999) Application of Coherent Risk Measures to Capital Requirements in Insurance. North American Actuarial Journal 3(2), 11-25.

Artzner, P., Delbaen, F., Eber, J.-M. and Heath, D. (1997) Thinking Coherently. Risk 10 (November), 68-71.

CMI Committee (1991) Continuous Mortality Investigation Reports No 12. Institute and Faculty of Actuaries, London.

Cummins, J.D. (1991) Statistical and financial models of insurance pricing and the insurance firm. Journal of Risk and Insurance 58, 261-302.

Daykin, C.D., Pentikainen, T. and Pesonen, M. (1994) Practical Risk Theory for Actuaries. Chapman and Hall, London.

Haberman, S. (1987) Long-Term Sickness and Invalidity Benefit: Forecasting and other Actuarial Problems. Journal of Institute of Actuaries 114, 467-533.

Haberman, S., and Pitacco E. (1999) Actuarial Models for Disability Insurance. CRC/Chapman and Hall, Boca Raton.

Haberman, S., Butt, Z. and Rickayzen, B.D. (2001) Multiple State Models, Simulation and Insurer Insolvency. Actuarial Research Paper No 136, City University, London. 
JoNES, B.L. (1997) Methods for the analysis of CCRC data. North American Actuarial Journal 1(2), 40-54.

Marceau, E. and Gaillardetz P. (1999) On life insurance reserves in a stochastic mortality and interest rate environment. Insurance: Mathematics and Economics 25, 261-280.

Renshaw, A.E. and Haberman, S. (1995) On the graduation associated with a multiple state model for permanent health insurance. Insurance: Mathematics and Economics 17, 1-17.

RickAYZEN, B.D. (2001) A Sensitivity Analysis of the Premiums for a Permanent Health Insurance (PHI) Model. Journal of Actuarial Practice 9, 189-212.

Ross, S.M. (1990) A Course in Simulation. Macmillan, New York.

Venables, N. and Ripley, B.D. (1999) Modern applied statistics with S-Plus. Springer-Verlag, New York, Second Edition, 284.

WiLKIE, A.D. (1995) More on a stochastic asset model for actuarial use. British Actuarial Journal 1, 777-964.

\section{STEVEn HABERMAN}

Cass Business School

City University

106 Bunhill Row, London EC1 Y 8TZ

United Kingdom

Phone: 442070408601

Fax: 442070408899

Email:s.haberman@city.ac.uk 